\title{
Erratum to: A Systematic Review of the Effects of Aromatherapy with Lavender Essential Oil on Depression
}

The editors of the Central Asian Journal of Global Health regretfully published the article "A Systematic Review of the Effects of Aromatherapy with Lavender Essential Oil on Depression" with a misspelled word in the title. This mistake has been corrected. The original article has been updated to reflect this change.

Jafar-Koulaee A, Elyasi F, Taraghi Z, Ilali ES, Moosazadeh M. A systematic review of the effects of aromatherapy with lavender essential oil on depression. Cent Asian J Glob Health. 2020;9(1). doi:10.5195/cajgh.2020.442.

Vol. 9, No. 1 (2020) | ISSN 2166-7403 (online)

DOI 10.5195/cajgh.2020.546 | http:/cajgh.pitt.edu

\section{(cc) $\mathbf{B Y}$}

New articles in this journal are licensed under a Creative Commons Attribution 4.0 United States License.

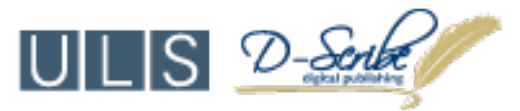

This journal is published by the University Library System of the University of Pittsburgh as part of its $\underline{\mathrm{D} \text {-Scribe Digital Publishing Program and is cosponsored by the University of Pittsburgh Press. }}$ 